\title{
GENDER DIFFERENTIATION OF INDIRECT SELF-DESTRUCTIVENESS
}

\author{
KONSTANTINOS TSIRIGOTIS ${ }^{1}$, WOJCIECH GRUSZCZYŃSKI², \\ and MARTA TSIRIGOTIS-MANIECKA ${ }^{3}$ \\ ${ }^{1}$ Jan Kochanowski University in Kielce, Piotrków Trybunalski, Poland \\ Department of Psychology \\ ${ }^{2}$ Medical University of Lodz, Łódź Poland \\ Neurotic and Stress Related Disorders Clinic \\ ${ }^{3}$ University of Technology, Wrocław, Poland \\ Organic and Pharmaceutical Technology Group, Chemistry Department
}

\begin{abstract}
Objectives: The objective of this study was to examine the sex (gender) differentiation of indirect self-destructiveness intensity and its manifestations, as well as relationships between indirect self-destructiveness and its manifestations (categories) and the psychological dimensions of masculinity and femininity, also from the point of view of assessing occupational health and safety. Materials and Methods: A population of 558 individuals (399 females and 159 males) aged 19-25 (mean age: 22.6) was studied. The Polish version of the "Chronic Self-Destructiveness Scale" (CS-DS) by Kelley adapted by Suchańska was used in order to examine indirect self-destructiveness and its manifestations. Gender testing applied the Polish version of the Bem Sex Role Inventory (BSRI) by Bem in its adaptation by Kuczyńska. Results: Males' scores are significantly higher than those of females for the majority of CS-DS scales/indices: Indirect Self-Destructiveness (general index), Poor Health Maintenance (A2), Lack of Planfulness (A4), and Helplessness, Passiveness (A5). Moreover, there are statistically significant correlations between CS-DS scales and the masculinity dimension (positive) as well as the femininity dimension (negative). Conclusions: Masculinity is a factor that may predispose towards indirectly self-destructive behaviors, while femininity is a factor protecting against those. The study results may prove useful in preventing indirectly and directly self-destructive behaviors as well as in therapy work with the individuals who display such tendencies or have made attempts on their own lives, in particular taking into account their being of a specific sex/gender and in the context of work (especially in difficult or dangerous conditions or both).
\end{abstract}

Key words:

Indirect self-destructiveness, Sex, Gender

\section{INTRODUCTION}

Behaviors (actions, acts, activity) of the human being may produce effects other than those intended or ones that are totally unexpected or even harmful to the human being himself or herself, that is independent of whether and to what extent the subject is aware of that as well as independent of the temporal perspective (now, immediately vs. later) or the kind of harm (physical vs. psychological harm).

The majority of authors frequently consider "self-destructive behaviors" to be behaviors categorized as directly self-destructive, most frequently self-mutilation, selfinflicted injury, and attempted or committed ("successful") suicide. Literature usually offers studies into direct

Received: April 23, 2012. Accepted: November 15, 2012.

Corresponding author: Konstantinos Tsirigotis, Department of Psychology, Jan Kochanowski University, Piotrków Trybunalski, Słowackiego 114/118, 97-300 Piotrków Trybunalski, Poland (e-mail: psyche1@onet.eu). 
self-destructiveness (self-mutilation, self-inflicted injury, attempted suicide, committed suicide) or into specific and separate behaviors being manifestations of what is nowadays called indirect or chronic self-destructiveness. For instance, it was found that in drug abusers' population direct self-destructiveness in males differs from direct selfdestructiveness in females [1].

While the issue of direct self-destructive behaviors (suicides, self-inflicted injuries etc.) is clear and raises no doubts, less acute and "subtle" forms of self-harm or impairing the quality or shortening the length of one's life or both are not immediately and directly noticeable (e.g. risky behaviors, addictions, neglects etc.). Less attention is usually paid to them, as many of those are treated as commonly (or at least often) occurring behaviors, and thus "normal" behaviors. Research into indirect self-destructiveness started in the mid-1980s and concerned mainly (if not solely) mentally healthy individuals.

Kelley describes chronic self-destructiveness as a generalised tendency to undertake behaviors, which increase the probability of negative consequences and decrease the probability of positive consequences for the subject [2]. For the purposes of this study, it was assumed that indirect or chronic self-destructiveness or both comprise behaviors, the probable negative effect of which, is intermediated by additional factors, while the relationship between a behavior and harm is perceived as probable.

Indirect self-destructiveness understood in such a way includes both: taking and abandoning specific actions; getting into hazardous and increased-risk situations (active form) or neglecting one's safety or health (passive form). Indirect self-destructiveness is a form of self-destruction characterized by an increased temporal distance between an action and its effect $[3,4]$.

There are several categories of indirectly self-destructive behaviors: transgression and risk, poor health maintenance, personal and social neglects, lack of planfulness, as well as helplessness and passiveness when facing problems or difficulties or both. Transgression and risk are behaviors violating social norms, such as school rules or principles of community life, as well as risky behaviors undertaken for a momentary pleasure, e.g. driving with bravado connected with a desire to impress others, feel appreciated, better or noticed, or gambling. This category also comprises succumbing to temptations, impulsiveness, and seeking risky excitation. Poor health maintenance encompasses behaviors harmful to one's health, such as excessive eating or drinking, missing medical appointments or ignoring physicians' recommendations. Personal and social neglects include, for instance, neglecting one's duties or matters (personally and interpersonally) important to the subject. Lack of planfulness is understood as acting mainly on the spur of the moment with nothing in view. Helplessness and passiveness is defined as giving up an action or not taking it in circumstances where such an action might end suffering or prevent danger [2-4].

There are few studies on the indirect self-destructiveness, and even fewer research done on the gender differentiation of indirect self-destructiveness, as generalised behavioral tendency done in a holistic way. Most of the studies carried out concern the direct self-destructiveness; it was found, for example, that females exhibit passive self-destructiveness [5]. Researches on individual, separate indirect self-destructive behaviors, found that males are more prone to risky such behaviors, such as alcohol abuse, not fastening seat belts in vehicles, performing dangerous jobs, and criminal activity [6,7]. There are positive correlations in males between drug abuse, aggressive or criminal behaviors, risky sexual behaviors, alcohol abuse and irresponsible behaviors as students or at work [8].

A result of a research project using the Chronic Self-Destructiveness Scale, it was found that female adolescents had lower scores than delinquent male ones but similar to the scores of young males not being delinquent adolescents [9]. 
Work is an important area of the human being's activity in life (allows one to provide for oneself, takes a great deal of one's time, and offers self-realization), hence indirect selfdestructiveness as a syndrome and/or its manifestations may occur also when performing one's job. In one of the few studies of indirect self-destructive behaviors at work researched foundry workers who used or did not use safety measures such as safety nets, hearing protection, safety goggles, gauntlets, heat-resistant clothes, and appropriate footwear. It was found that features of a specific protective measure itself are of the secondary importance as compared with the subjects' traits $[3,10]$. One of those traits may certainly be indirect self-destructiveness syndrome. It is worth mentioning at that point that males account for about $95 \%$ of accident fatalities at work [6,11].

It is a well-known fact that males display more self-destructive behaviors but most research and data target direct self-destructiveness. In the world literature there is almost no study into the gender (sex) differentiation of indirect self-destructiveness as a generalised tendency done in a comprehensive, holistic manner.

\section{OBJECTIVE AND HYPOTHESES}

The objective of this study is to examine the gender (sex) differentiation of the intensity of indirect self-destructiveness and its manifestations, as well as relationships between indirect self-destructiveness and its manifestations (categories) and the psychological dimensions of masculinity and femininity, also from the point of view of assessing occupational health and safety. Therefore, it has been assumed that:

1. The intensiveness of indirect self-destructiveness, as a generalised behavioral tendency, is higher in males than in females.

2. Indirect self-destructiveness, as a generalised behavioral tendency, is related to the psychological dimension of masculinity.

\section{MATERIALS AND METHODS}

A population of 558 individuals (399 females and 159 males) aged 19-25 (mean age: 22.6) was studied. Females were aged from 19 to 24 (mean age: 22.4), while males' ages ranged from 19 to 25 years (mean age: 22.8). The subjects were students of higher education institutions in Łódź and Świętokrzyskie Poland. All of the subjects were mentally and physically healthy.

The examination of indirect self-destructiveness and its manifestations in the studied population used the Polish version of the "Chronic Self-Destructiveness Scale" (CS-DS) by Kelley [2], adapted by Suchańska [3]. In order to examine chronic (indirect) self-destructiveness as a generalised tendency, Kelley created a research tool comprising four categories of behavior; the final version is a list of 52 statements for males and females. The Polish version of the tool, as the original one, is characterized by high reliability and validity, and includes the following categories: Transgression and Risk (A1; e.g. I like jobs with an element of risk; I have done dangerous things just for the thrill of it; Lots of laws seem made to be broken), Poor Health Maintenance (A2; e.g. I am familiar with basic first-aid practices), Personal and Social Neglects (A3; I usually meet deadlines with no trouble), Lack of Planfulness (A4; I seldom have even minor accidents or injuries), and Helplessness, Passiveness when facing problems/difficulties (A5; Sometimes I don't seem to care what happens to me), the scores of which are summed up to provide one general indirect self-destructiveness score. Scores up to 103 are considered low, 104-160 is the range of medium scores, while scores above 160 are regarded as high [2,3]. Gender testing applied the Polish version of the Bem Sex Role Inventory (BSRI) by Bem [12,13] adapted by Kuczyńska [14,15]. Scores achieved in two dimensions (femininity and masculinity) allow classifying subjects as representing four types of gender: sex-typed individuals (masculine males, feminine females), androgynous individuals (having both feminine and masculine traits), 
cross-sex-typed or sex-reversed individuals (masculine females, feminine males), and undifferentiated individuals. Both the original and Polish BSRI versions are characterized by high reliability and validity [12-15].

The statistical analysis of the received results applied descriptive and statistical inference methods. In order to determine the mean value for quantitative traits, the statistical mean was calculated $(\mathrm{x}, \mathrm{M})$, while the dispersion measure was the standard deviation (SD). The conformity of quantitative traits' distributions with the normal distribution was evaluated using the Shapiro-Wilk test. Due to the lack of conformity of dependent variables' distributions with the normal distribution, the statistical processing of acquired results used the non-parametric Mann-Whitney U significance test. In order to examine relationships between the studied variables, Kendall's "tau" $(\tau)$ correlation coefficient was applied. So as to examine the structure in relationships between variables and possibly reduce the number of variables, exploratory factor analysis was performed employing the principal component analysis method and normalized varimax rotation. Factor analysis was made separately for the group of females and the group of males in order to examine the structure of indirect self-destructiveness for each sex. For all the analyses, the maximum acceptable type I error was assumed at $\alpha=0.05 ; \mathrm{p} \leq 0.05$ was considered statistically significant. The statistical analyses were carried out using the statistical Statistica PL 8.0 for Windows [16] package.

In order to enable inter-profile comparisons, raw scores achieved by the subjects were converted into standardized ones (ten scale, $\mathrm{T}$ units).

\section{RESULTS}

Table 1 and Figure 1 present the results achieved by males and females in the CS-DS. As can be seen, the general (global) indicator of indirect self-destructiveness as well as scores in all the scales fluctuate around mean scores. Only the scores for the Helplessness and Passiveness (A5) scale exceed the range of medium ones.

The profile for males is higher than that for females, which means that males' scores are higher than females' in all the scales, while Table 1 shows that the majority of scales are statistically significantly higher; therefore, it may be inferred that males are characterized by higher indirect self-destructiveness as a generalised behavioral tendency and display more indirectly self-destructive behaviors.

Table 2 presents correlation coefficients (Kendall's tau) between the subjects' scores in the CS-DS scales and their scores in the BSRI dimensions. It can be observed that there are statistically significant correlations between CS-DS scales and the masculinity dimension as well as the femininity one.

Table 1. Comparison of the results obtained by females and males in the Chronic Self-Destructiveness Scale (CS-DS)

\begin{tabular}{lrrrrrc}
\hline \multirow{2}{*}{ Variables } & \multicolumn{2}{c}{ Women } & \multicolumn{2}{c}{ Men } & \multicolumn{2}{c}{ Significance } \\
\cline { 2 - 7 } & \multicolumn{1}{c}{ M } & \multicolumn{1}{c}{ SD } & \multicolumn{1}{c}{ M } & \multicolumn{1}{c}{ SD } & Mann-Whitney U & $\mathrm{p}$ \\
\hline Indirect Self-Destructiveness & 121.41 & 17.11 & 126.73 & 22.57 & 10516.50 & 0.01 \\
A1 - Transgression, Risk & 39.04 & 8.03 & 39.47 & 9.86 & 11934.00 & ns. \\
A2 - Poor Health Maintenance & 27.20 & 6.18 & 28.73 & 6.73 & 10503.00 & 0.03 \\
A3 - Personal and Social Neglects & 28.22 & 5.47 & 28.77 & 6.99 & 12105.00 & ns. \\
A4 - Lack Of Planfulness & 18.43 & 4.47 & 21.70 & 5.02 & 7807.50 & $\mathrm{p}<0.001$ \\
A5 - Helplessness, Passiveness & 6.63 & 1.98 & 8.30 & 1.99 & 6817.50 & $\mathrm{p}<0.001$ \\
\hline
\end{tabular}

M - mean; SD - standard deviation; ns - non-significant. 


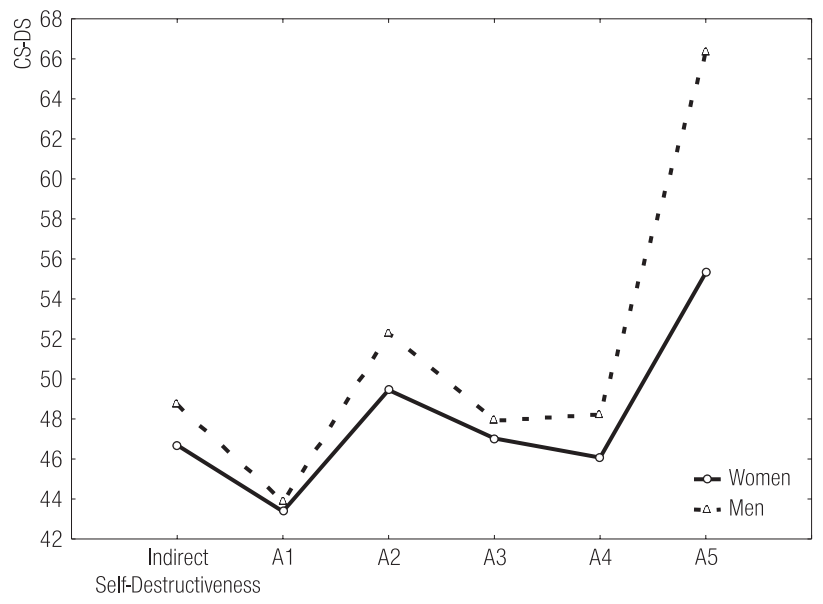

A1 - Transgression and Risk; A2 - Poor Health Maintenance;

A3 - Personal and Social Neglects;

A4 - Lack of Planfulness; A5 -Helplessness, Passiveness.

Fig. 1. Profiles of males and females in Chronic SelfDestructiveness Scale (CS-DS)
It should be noted that all the correlation coefficients between the subjects' scores in the CS-DS scales and their scores in the masculinity dimension are positive, while negative between their scores in the CS-DS scales and scores in the femininity dimension. Moreover, different CS-DS scales significantly correlate with the masculinity dimension (Indirect Self-Destructiveness, A1 - Transgression and Risk, and A5 - Helplessness, Passiveness) and the femininity dimension (Indirect Self-Destructiveness, A3 - Personal and Social Neglects, and A4 - Lack of Planfulness).

The factor analysis of the scores achieved in the CS-DS by females (Table 3) revealed two factors; for the first factor the highest factor loading occurred for Helplessness, Passiveness (A5; factor loading: 0.839), while for the second - Poor

Table 2. Correlation coefficients between the Chronic Self-Destructiveness Scale (CS-DS) and the Bem Sex Role Inventory (BSRI) variables

\begin{tabular}{lcccc}
\hline \multirow{2}{*}{ Variables } & \multicolumn{2}{c}{ Masculinity } & \multicolumn{2}{c}{ Femininity } \\
\cline { 2 - 5 } & $\begin{array}{c}\text { correlation } \\
(\tau)\end{array}$ & $\begin{array}{c}\text { significance } \\
(\mathrm{p})\end{array}$ & $\begin{array}{c}\text { correlation } \\
(\tau)\end{array}$ & $\begin{array}{c}\text { significance } \\
(\mathrm{p})\end{array}$ \\
\hline Indirect Self-Destructiveness & 0.177 & $\mathrm{p}=0.003$ & -0.151 & $\mathrm{p}=0.010$ \\
A1 - Transgression, Risk & 0.400 & $\mathrm{p}<0.000$ & -0.026 & ns. \\
A2 - Poor Health Maintenance & 0.047 & $\mathrm{ns.}$ & -0.048 & $\mathrm{ns.}$ \\
A3 - Personal and Social Neglects & 0.083 & $\mathrm{ns.}$ & -0.204 & $\mathrm{p}=0.001$ \\
A4 - Lack of Planfulness & 0.079 & $\mathrm{ns.}$ & -0.252 & $\mathrm{p}<0.000$ \\
A5 - Helplessness, Passiveness & 0.361 & $\mathrm{p}<0.000$ & -0.081 & $\mathrm{~ns}$. \\
\hline
\end{tabular}

ns - non-significant.

Table 3. Factor analysis of the results obtained by females in the Chronic Self-Destructiveness Scale (CS-DS)

\begin{tabular}{lcc}
\hline \multicolumn{1}{c}{ Factors / variables } & Factor loadings & Variance explained \\
\hline Factor I & & $40.83 \%$ \\
A5 - Helplessness, Passiveness & 0.839 & \\
A3 - Personal and Social Neglects & 0.655 & \\
A4 - Lack of Planfulness & 0.642 & $20.71 \%$ \\
Factor II & & \\
A2 - Poor Health Maintenance & 0.760 & \\
A1 - Transgression and Risk & 0.733 & $61.54 \%$ \\
Total & & \\
\hline
\end{tabular}


Table 4. Factor analysis of the results obtained by males in the Chronic Self-Destructiveness Scale (CS-DS)

\begin{tabular}{lcc}
\hline \multicolumn{1}{c}{ Factors / variables } & Factor loadings & Variance explained \\
\hline Factor I & & $53.49 \%$ \\
A4 - Lack of Planfulness & 0.866 & \\
A3 - Personal and Social Neglects & 0.806 & \\
A2 - Poor Health Maintenance & 0.711 & \\
A1 - Transgression and Risk & 0.680 & \\
A5 - Helplessness, Passiveness & 0.555 & $53.49 \%$ \\
Total & & \\
\hline
\end{tabular}

Health Maintenance (A2; factor loading: 0.760). In turn, the factor analysis of the results for males (Table 4) produced only one factor in which all the scales were grouped with the highest factor loading occurring for Lack of Planfulness (A4; factor loading: 0.866).

\section{DISCUSSION}

The received results indicate that the intensity of indirect self-destructiveness, as a generalised behavioral tendency (or syndrome), is higher in males than it is in females. It can be assumed that males more frequently or intensely (or both) display tendencies and behaviors which, despite being convenient or pleasant at the time, may prove, physically or psychologically, harmful in the long run. Suchańska obtained similar results [3] too, although her study neither provided information on the significance of that difference nor raised the issue of sex (gender) differences. There are also interesting results of other research projects where it was revealed that females exhibit passive self-destructiveness [5] and are less prone to suicides, which is consistent with the results of another study of ours [17]. Furthermore, the majority of specific categories the indirectly self-destructive behaviors are more intense in males as well.

It is also worth emphasizing that the masculinity dimension is associated with indirect self-destructiveness as a generalised behavioral tendency as well as transgressive and risky behaviors, and helplessness. It is the other way round for femininity, the higher the femininity loading is, the lower the indirect self-destructiveness occurs as a generalised tendency, and thus the lesser the personal and social neglects and lack of planfulness are.

That general behavioral tendency (syndrome or psychological trait) consists of at least a few categories of behaviors that are potentially harmful to the subject.

A typical, or even textbook, example of indirectly selfdestructive behaviors is transgression and risk (A1); it is a manner of the individual's behavior that is against generally accepted social norms and values, hence it often violates the principles of community life. That may also include, among others, gambling or driving with bravado, or any other risky behaviors that enable an increased adrenaline level in the human body in order to enjoy a fleeting pleasure. Transgressive behaviors also encompass taking drugs, drinking alcohol, and smoking. Such behaviors contribute, more than others, to revealing the limits and conditions of self-destructiveness. As can be seen, the categories of behaviors that constitute ultimate examples of self-destructive behaviors (risk) in males are connected with the psychological dimension of masculinity.

The above statements are consistent with those of other studies that demonstrated that males are more prone to such risky behaviors (actions) as abusing alcohol, not fastening one's seat belts in cars, performing dangerous jobs, and pursuing criminal activity $[6,7]$. 
Males also run a three times higher risk of sudden death (accidents, suicides, homicides), they fall victims to violence and break the law about three times as often as females do. Divergence is particularly considerable in case of violent crimes with males more frequently being both perpetrators and victims of such acts $[6,11,18]$. The differences are especially noticeable in case of delinquent adolescents. The CS-DS results of female delinquent adolescents were lower than male delinquent adolescents but similar to the results of young males not being delinquent adolescents [9]. Such differences, however, occur also in the population of non-delinquent adolescents: young males more often become victims of accidents, including traffic ones (mainly involving motorbikes), than young females, which is connected with taking excessive risks [19]. In males, there are positive correlations between indirect self-destructiveness and exhibiting risky behaviors in six consecutive months, including drug abuse, aggressive and/or criminal behaviors, risky sexual behaviors, alcohol abuse and irresponsible behaviors as students or at work; while in females, indirect self-destructiveness was associated solely with the expected displaying of alcohol abuse and irresponsible behaviors as students or at work [8]. The so-called gender difference concerning fatalities at work (95\% of victims are males) explains from $2 \%$ to $3 \%$ of the total gender difference in mortality in the United States [6,11]. In Poland, the studies revealed that indirect self-destructiveness is higher in professional drivers characterized by higher accident rates than in those with lower accident rates [3].

One may hazard a guess that gender (sex) differences, even in case of such a dramatic manifestation of direct self-destructiveness such as suicide, may result from higher indirect self-destructiveness in males. Males more often commit suicides, although it is females who more frequently make attempts on their lives. Females are less prone to suicide than males $[5,6,17,20]$ and are the "survivors" of suicide attempts.
Thus, there are clear gender (sex) differences in the scope of such indirectly self-destructive behaviors.

The Poor Health Maintenance category (A2) contains, among others, disregarding physician's instructions and recommendations concerning coping with specific complaints as well as failure to take actions related to disease prevention, which may ultimately contribute to the worsening of symptoms and signs or even death. Poor health maintenance manifestations also include premature discontinuation of treatment, a tendency to forget about appointments made or various procedures, as well as irregular taking of medications or giving up the medications completely, which is prominent in males. Other studies produced similar results, for example, males are more prone to avoiding regular contact with physicians [6,21], while females find it more difficult to avoid contact with physicians, irrespective of their condition, as, for instance, numerous contraceptives are available only if prescribed [6,22]. Females are more "accustomed" to using health care and are more "trained" due to their necessary regular gynecological examinations. Females more frequently and willingly seek help in case of health, life, and/or psychological problems than males who often consider such behavior to be "unmanly" and signifying weakness [17,23]; thus, those neglects by males have graver health consequences, which is reflected, among others, in the fact that after suicide attempts they require more intensive care than females and these attempts more frequently lead to death [17,24].

The Personal and Social Neglects scale (A3) assesses neglecting matters of various importance - from trivial ones to those posing an immediate threat to health or even life. Such behaviors of the subject may result in failures or even disasters in one's life, the causes of which the subject may not be aware of. That means subjects more frequently experience personal and social failures due to abandoning actions that might improve their personal and social situation or their interpersonal relations. An example may 
be the so-called series of misfortunes, i.e. a manner of acting that decreases the probability of succeeding in one's actions according to the concept of cognitive dissonance; when experiencing failures, the subject seeks further failures in order not to face a cognitive dissonance situation that might result from achieving success. That particularly dramatic way of regulating one's expectations by means of the so called strategic failures proves willingness to bear high psychological costs for the sake of a sense of safeness [3]. The femininity dimension seems to be a factor protecting against such problems.

Lack of Planfulness (A4) is often connected with tendencies to forget about or ignore matters that are significant and important at a certain point of life as well as to be careless in everyday life. That may be associated with negative events, apparently unconnected with the subject's actions, but may directly contribute to endangering the individual's health or life. Femininity is a protective factor in respect of such attitudes and behaviors. One may describe that phenomenon quite vividly by stating that studied males seem to be "careless, cheerful boys" as opposed to females who appear as "constantly worrying demons for work and conscientiousness" [25,26]. The above statement may also be substantiated by the factor analysis of males' scores: in the only factor revealed by that, the highest factor loading occurred for lack of planfulness (A4).

The fact that the factor analysis produced two factors for females may suggest higher internal differentiation and psychological complexity of females. It may also be assumed that the essence and structure of indirect selfdestructiveness differ between females and males.

Some authors [fc. 6,11] believe that dangerous work is an important factor affecting gender differences in accident-caused mortality because males, more often than females, perform dangerous jobs/tasks (e.g. operating dangerous equipment or working in its vicinity). Undoubtedly, dangerous jobs/actions constitute a factor increasing the probability of accidents at work. Accidents at work, however, results from an interaction between "external", environmental or situational factors and "internal", personality-related ones. A set of those psychological factors may be the indirect self-destructiveness syndrome. In a work situation, transgression and risk (A1) as well as the lack of planfulness (A4) may prove especially unfavorable. Those are closely connected with the psychological dimension of masculinity or even the male gender (sex) itself.

The subjects achieved the highest scores for the Helplessness and Passiveness index (A5) in case of which males also ranked higher than females. That may prove lacking motivation to take specific actions or abandoning them completely when such actions might protect the individual from danger or contribute to ending the suffering of others. That may often contribute to behaviors connected with avoiding or abandoning activities in situations in life that require involvement or taking specific actions aimed at resolving existing problems. Attention ought to be drawn to the results of other studies revealing a relationship between indirect self-destructiveness and a sense of impotence and hopelessness [8]. That helplessness is associated with masculinity.

The increased lack of planfulness and helplessness in males may prove useful in explaining their higher intensity of indirect self-destructiveness. As already mentioned, males more seldom seek assistance and that is possibly why they feel more helpless in problem situations; and maybe that is why their strategies of coping are more (indirectly) self-destructive than those of females. Kelley [27] says that chronic self-destructiveness is not androgynous but rather sex-typed; the results of this study indicate that chronic or indirect self-destructiveness is rather masculine. The biological sex and the psychological dimension of gender (sex) constitute equally good predictors of indirect self-destructiveness, being complementary to each other. 


\section{CONCLUSIONS}

The aim of this study was to investigate the indirect selfdestructiveness, as a generalised behavioral tendency, in a holistic way (rather than individual, separate indirect self-destructive behaviors) and its relationship with the biological sex and psychological gender, in the aspect of the career too.

Speaking in the most general terms, it may be assumed that the masculinity dimension is characterized by definitely higher predispositions to risky and potentially harmful behaviors than the femininity one.

The masculinity dimension creates distinct predispositions to display behaviors that are against norms and values generally accepted and respected by the society. Such a manner of behavior often entails the possible risk or occurrence of adverse consequences. It may be chosen when one wants to experience a momentary pleasure or feel a "prickle" of excitement accompanying a performed action.

It can be observed that in particularly difficult situations or those that require specific actions to be taken, a predominance of masculine psychological traits allows for giving up, feeling discouraged or lacking willingness to undertake activity that might significantly contribute to ending, solving or eliminating an existing problem or danger. The femininity dimension is associated with carefulness, cautiousness, attention, and planning related to trifling everyday actions and duties as well as matters of the crucial importance to one's life. Masculinity is connected with the attitudes and behaviors that prove to be harmful to the subject in the psychological dimension and over time. In turn, femininity predisposes to good adaptation: the higher the femininity is, the lower the indirect self-destructiveness occurs. Basing on the above, it can be assumed that masculinity is a factor that may predispose to indirectly self-destructive behaviors, while femininity is a factor protecting against those.
The results of this study may prove useful in preventing indirectly and directly self-destructive behaviors as well as in therapy work with individuals who display such tendencies or have made attempts on their own lives, in particular taking into account their being of a specific sex/gender. In a work situation, especially in dangerous conditions, an important factor associated with indirect self-destructiveness (and accident rate) appears to be the psychological dimension of masculinity and the male sex itself.

It seems that testing methods using the indirect self-destructiveness scale may be recommended for admittance to work in difficult or dangerous (harmful to health) conditions.

\section{REFERENCES}

1. Saxon S, Kuncel E, Kaufman E. Self-destructive behavior patterns in male and female drug abusers. Am J Drug Alcohol Abuse 1980;7(1):19-29.

2. Kelley K, Byrne D, Przybyla DPJ, Eberly C, Eberly B, Greendlinger V, et al. Chronic Self-Destructiveness: Conceptualization, measurement, and initial validation of the construct. Motiv Emotion 1985;9,2:135-51.

3. Suchańska A. Psychological manifestations and conditions of indirect self-destructiveness. Poznań: UAM; 1998 [in Polish].

4. Suchańska A. In searching of explanations of self-destroying. Self-destroying and self-caring competencies Forum Oswiat 2001;2,25:61-73 [in Polish].

5. Clifton AK, Lee DE. Self-destructive consequences of sex-role socialization. Suicide 1976;6(1):11-22.

6. Brannon L. Gender: Psychological Perspectives. Boston: Allyn \& Bacon; 2011.

7. Eckahrdt MJ, Hardford TC, Kaelber CT, Parker ES, Rosenthal LS, Ryback RS, et al. Health hazards associated with alcohol consumption. JAMA 1981;246:648-66.

8. Kelly DB, Rollings AL, Harmon JG. Chronic self-destructiveness, hopelesseness, and risk-taking in college students. Psychol Rep 2005;96(1)3:620-24. 
9. Dolin IH, Kelly DB, Beasley TM. Chronic self-destructive behavior in normative and delinquent adolescents. J Adolesc 1992;15:57-66.

10. Tyszka T, Bukowski K. Do the employees expose themselves deliberately? Przegl Psychol 1991;31(2):293-311 [in Polish].

11. Waldron I. Effects of labor force participation on sex differences in mortality and morbidity. In: Frankenhaeuser M, Lundberg U, Chesney M, editors. Women, work, and health: Stress and opportunities. New York: Plenum Press; 1991. p. 17-38.

12. Bem SL. The measurement of psychological androgyny. J Consult Clin Psychol 1974;42:155-62.

13. Bem SL. Bem Sex Role Inventory: Professional Manual. Palo Alto, CA: Consulting Psychologists Press; 1981.

14. Kuczyńska A. Psychological Gender. Theoretical foundations, empirical data and measurement tool. Warszawa: Polskie Towarzystwo Psychologiczne; 1992 [in Polish].

15. Kuczyńska A. Inventory for psychological gender assessment. Warszawa: Polskie Towarzystwo Psychologiczne; 1992 [in Polish].

16. StatSoft Polska. Statistica PL. Kraków: StatSoft; 2007.

17. Tsirigotis K, Gruszczyński W, Tsirigotis M. Gender differentiation in methods of suicide attempts. Med Science Monit 2011;17,8:65-70.

18. U.S. Bureau of the Census. Statistical abstracts of the United States, 1996. Washington, DC: U.S. Government Printing Office; 1996.

19. Tursz A, Courtecuisse V, Jeanneret O, Sand A. Risk-taking behavior and accidents in adolescence in developed countries. Rev Epidemiol Sante Publique 1986;34(2):81-8 [in French].
20. Kessler RC, Mcrae JA Jr. Trends in the relationship between sex and attempted suicide. J Health Soc Behav 1983;24:98110.

21. Muller CF. Health care and gender. New York: Russell Sage Foundation; 1990.

22. Kane P. Women's health: From womb to tomb. New York: St. Martin's Press; 1991.

23. Tsirigotis K., Gruszczyński W. Psycho(patho)logical functioning of Adult Children of Alcoholics (ACoAs), outpatients of Mental Health Clinic. Clin Exper Med Let 2009;50(2):81-8.

24. Stefanello S, da Silva Cais CF, Mauro MLF, de Freits GVS, Botega NJ. Gender differentiation in suicide attempts: preliminary results of the multisite intervention study on suicidal behavior (SUPRE-MISS) from Campinos, Brasil. Rev Bras Psiquiatr 2008;30(2):139-43.

25. Lewik-Tsirigotis E, Tsirigotis K. Personality traits of teacher candidates, In: Mikołajewicz W, editor. Education and professional training of teachers (for) the alternative education. Kraków: IMPULS; 2001. p. 138-49 [in Polish].

26. Tsirigotis K, Lewik-Tsirigotis E. The issue of the gender differantiation of personality functioning of teacher candidates. Nauczyciel Szkola 2004;1-2(22-23):175-93 [in Polish].

27. Kelley K. Perspectives on females, males and sexuality. In: Kelley K, editor. Females, males and Sexuality. Theories and research. Albany: New York Press; 1987. p. 1-12.

This work is available in Open Access model and licensed under a Creative Commons Attribution-NonCommercial 3.0 Poland License - http://creativecommons.org/ licenses/by-nc/3.0/pl/deed.en. 